\title{
The History and Future of Deep Brain Stimulation
}

\author{
Jason M. Schwalb* and Clement Hamani ${ }^{\dagger}$ \\ *Department of Neurological Surgery, University of Rochester, Rochester, NY 14642; ${ }^{\dagger}$ Division of Neurosurgery, University of \\ Toronto, Ontario, Canada M5T 2S8
}

\begin{abstract}
Summary: The advancement of electrical stimulation of the central nervous system has been a story of fits and bursts with numerous setbacks. In many ways, this history has paralleled the history of medicine and physics. We have moved from anecdotal observation to double-blinded, prospective randomized trials. We have moved from faradic stimulation to systems that lie com-
\end{abstract}

pletely under the skin and can deliver complex electrical currents to discrete areas of the brain while controlled through a device that is not much bigger than a PDA. This review will discuss how deep brain stimulation has developed into its current form, where we see the field going and the potential pitfalls along the way. Key Words: DBS, history, cerebral localization.

\section{EARLY HISTORY}

Electrical stimulation has been used since ancient times to modulate the nervous system. The electric ray Torpedo nobiliana was so named by the Romans for its ability to cause torpor. ${ }^{1}$ The Greeks named the same animal narke due to its ability to numb or narcotize its prey, or anyone foolish enough to catch it in his nets. ${ }^{2}$ In 46 C.E., Scribonius Largus suggested applying the live ray to the head of a patient suffering from a headache. ${ }^{3}$ This remedy was later used for hemorrhoids, gout, depression, and epilepsy. Fortunately, we have progressed, although even in 18th Century North America, electric fish were used for pain control. ${ }^{3}$

The first major steps in such progress were the realizations that the brain is an electrical organ and that the brain is not homogenous. Although Hippocrates observed that damage to the veins of the brain can cause contralateral seizures, it was believed that the brain was a homogenous mass without discrete function for over two millennia. ${ }^{4}$ This incorrect model was finally put to rest by the seminal observations of Fritsch and Hitzig. ${ }^{5}$ Similar to Hippocrates, Fritsch and Hitzig $^{5}$ noted contralateral convulsions when dressing a head wound in 1864 . However, by this time, the voltaic cell had been invented, and Michael Fara-

Address correspondence and reprint requests to: Jason M. Schwalb, MD, Department of Neurological Surgery, University of Rochester School of Medicine and Dentistry, 601 Elmwood Avenue, Box 670, Rochester, NY 14642. E-mail: jason_schwalb@urmc.rochester.edu. day's law had led to the development of the generator. Peripheral applications of electrical current had become common in the 19th Century for anesthesia and a variety of medical ailments (FIG. 1). ${ }^{1,6}$ During one such application, Hitzig noted contralateral eye movements with strong electrical stimulation of the scalp. Because it was considered academic heresy to challenge this dogma of the "unexcitable cortex," Fritsch and Hitzig ${ }^{5}$ performed a series of experiments on dogs at Hitzig's home. Publishing their results in 1870, they found that they could elicit graded responses, from small arm movements to generalized tonic clonic seizures, based on the amount of current applied (available in English translation ${ }^{6}$ ).

Soon thereafter, in 1874, in Cincinnati, Bartholow ${ }^{7}$ applied current to the brain of a terminal patient whose scalp and cranium had eroded due to basal cell carcinoma (FIGS. 2 and 3). ${ }^{6}$ Initially, these experiments went well, eliciting contralateral movements. However, in the last set of experiments, Bartholow ${ }^{7}$ induced seizures. Over the next several days, they became recurrent and this female patient died. An autopsy showed thrombosis of the transverse sinus as well as a subdural empyema. Bartholow ${ }^{7}$ attributed these findings and her death to her underlying disease, but was roundly condemned by antivivisectionists, the American Medical Association, and the British Medical Journal, among others, for three reasons: 1) the patient was mentally retarded and not competent to give informed consent, 2) she suffered pain and discomfort as a result of the experiment, and 3) the experiment hastened her demise. 


\section{TEX10 FARADIC ELECTRIFIER.}

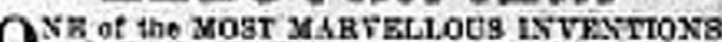

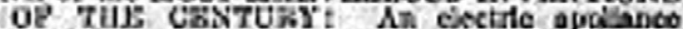

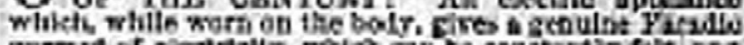

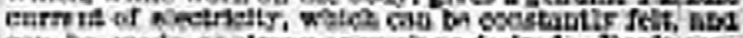

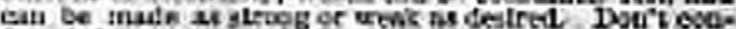
fostal thes with as-ralind migeeds sed calranes appil. atrove that lave bag wald in this oity.

A.1 satos of IBhotumntlam, Disnagra or

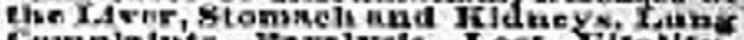

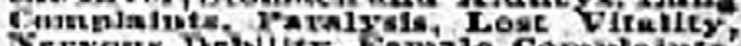
Kervans Dobilits, Female Conalaleiars?

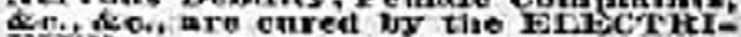
Fiver.

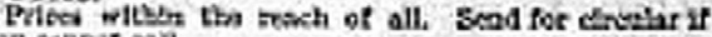
sou cannat ell.

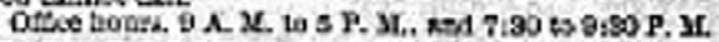

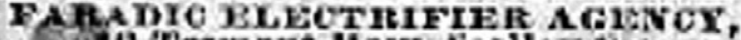

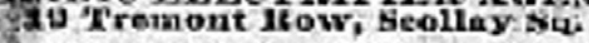

FIG. 1. Advertisement for electrical stimulation in the Boston Globe from 1882 .

The next publication of electrical stimulation of the human brain was by Horsley ${ }^{8} 10$ years later. He determined that there was functional tissue within an encephalocele via electrical stimulation. In 1887, he performed the first electrocorticography for epilepsy surgery at the suggestion of Hughlings Jackson. ${ }^{9}$ Electrocorticography was further developed by many of the giants of neurosurgery: Keen, Krause, Sherrington, and Penfield. How- ever, it took another 80 years before the technology advanced to the point that one could consider implantation of stimulating electrodes with which a patient could walk around.

Before there was long-term stimulation, there was ablation. Horsley had performed cortical ablations of the pyramidal system for movement disorders in $1890 .^{10}$ Although these procedures were successful in abolishing abnormal movements, the patients were left with significant paresis as a result. It was believed by many leading neuroscientists and neurosurgeons that surgery on the extrapyramidal system would result in impaired consciousness and/or weakness (reviewed in reference 11). Meyers first tested lesions of the basal ganglia to alleviate movement disorders in 1939; however, because these were open procedures before the advent of the operating microscope, the morbidity was significant with a $12 \%$ risk of mortality (FIG. 4).

\section{THE ADVENT OF HUMAN STEREOTAXIS}

This all changed with the development of the stereotactic frame by Spiegel et al. ${ }^{12}$ in 1947 (FIG. 5). Although Horsley and Clarke $^{13}$ had designed an earlier stereotactic frame for use in animals using surface landmarks, it was not very accurate due to variability between subjects. ${ }^{11,13,14}$ Spiegel et al. ${ }^{12}$ used pneumoencephalograms to determine Cartesian coordinates of structures around the ventricles. In their first article describing the apparatus, they reported using the device for

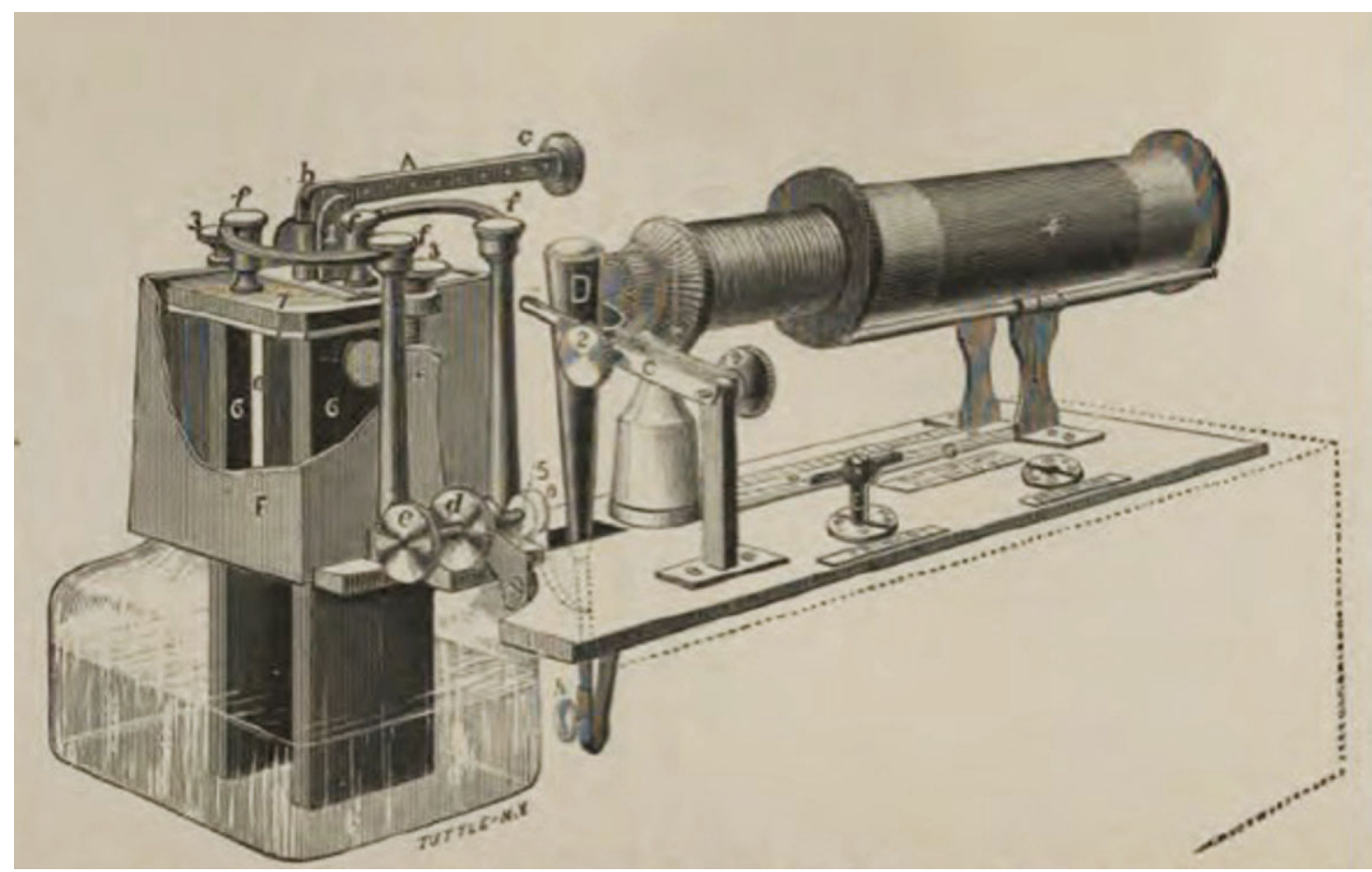

FIG. 2. Bartholow's ${ }^{7}$ faradic current source. 


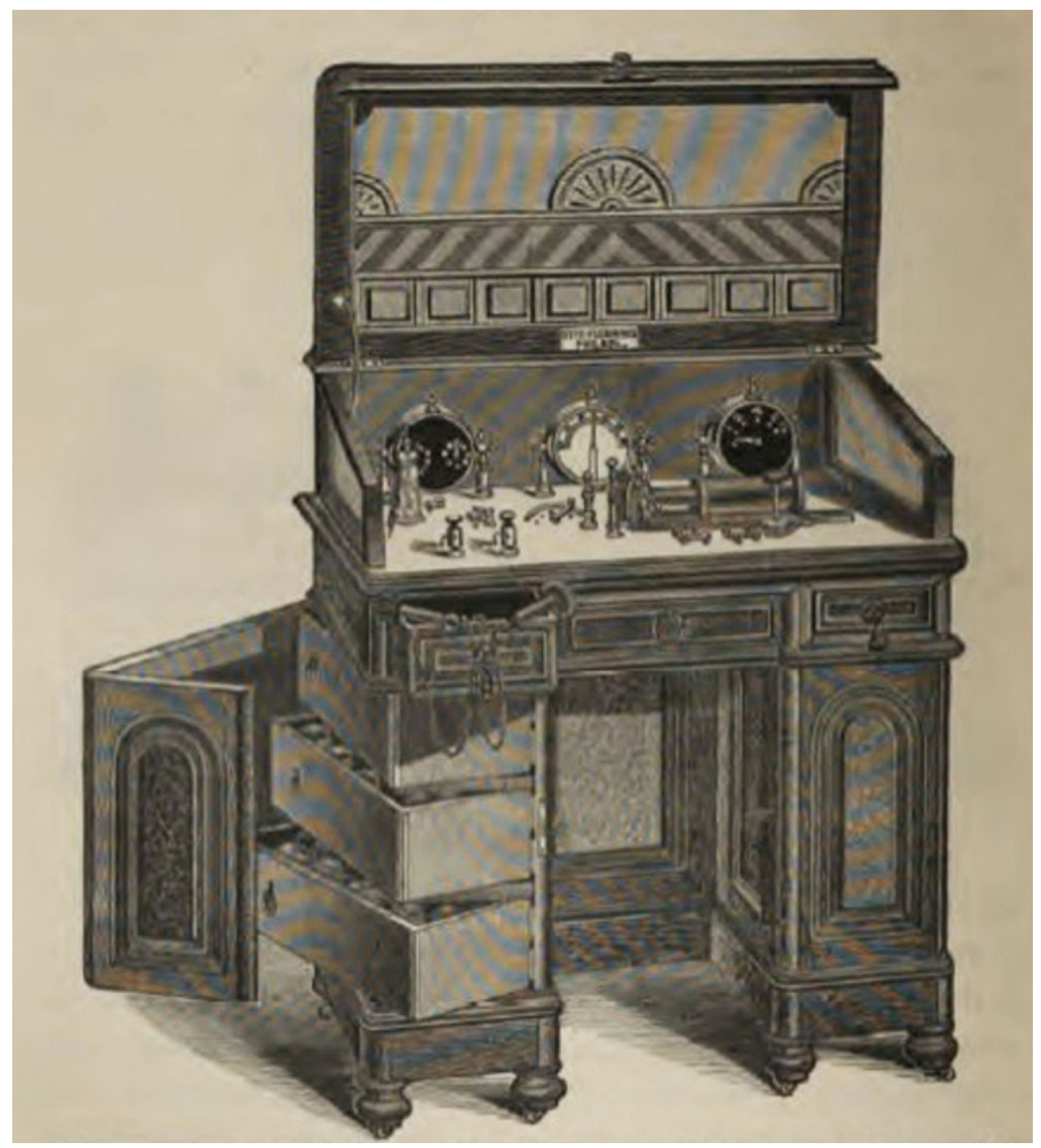

FIG. 3. Early pulse generator. ${ }^{7}$

psychosurgery, pain (including phantom limb pain), pallidotomy for abnormal movements, electrocoagulation of the gasserian ganglion for trigeminal neuralgia and withdrawal of fluid from cystic tumors. They went on to develop a stereotactic atlas of the human brain to guide surgery. With these new tools, surgery could be performed with less than $1 \%$ mortality. ${ }^{11}$

However, even with the development of multiple frames, atlases, and lesioning techniques, there were (and are) issues of inaccurate targeting with stereotaxis. This may be due to differences in topographic relationships between the structures of interest and the ventricles between subjects, or it may be due to brain shift from air entry and cerebrospinal fluid egress during the procedure. Electrical stimulation was used to determine the proximity of vital structures and thereby avoid them before creating stereotactic lesions as early as $1951,{ }^{15,16}$ if not earlier. ${ }^{17}$ Long-term recording was used for several days before creating thalamotomies by $1960 .{ }^{18}$ True mi- croelectrode recording with low impedance semi-microelectrodes was pioneered by Able-Fessard in 1961. ${ }^{19}$ These tools, as well as computer modeling, allowed for the development of neurophysiologic atlases of the human brain..$^{20,21}$

There was an explosion of stereotactic functional neurosurgery in the late $1950 \mathrm{~s}$, although, even then, the techniques were embraced more in Europe and Canada than in the United States. ${ }^{21}$ Cingulotomy, anterior capsulotomy and subcaudate tractotomy were used for pain and psychiatric disease as an alternative to the ice-pick frontal leukotomies performed by Walter Freeman. ${ }^{21}$ Pallidotomy and thalamotomy were used for Parkinson's disease (PD) and dystonia. The stage was set for electrical stimulation for movement disorders and psychiatric disease with the development of the first totally implantable pacemaker by Chardack et $\mathrm{al}^{22}$ in 1960 and the radiofrequency-driven spinal cord stimulator by Shealy in $1967 .{ }^{1}$ However, surgery for PD ground to a halt with 


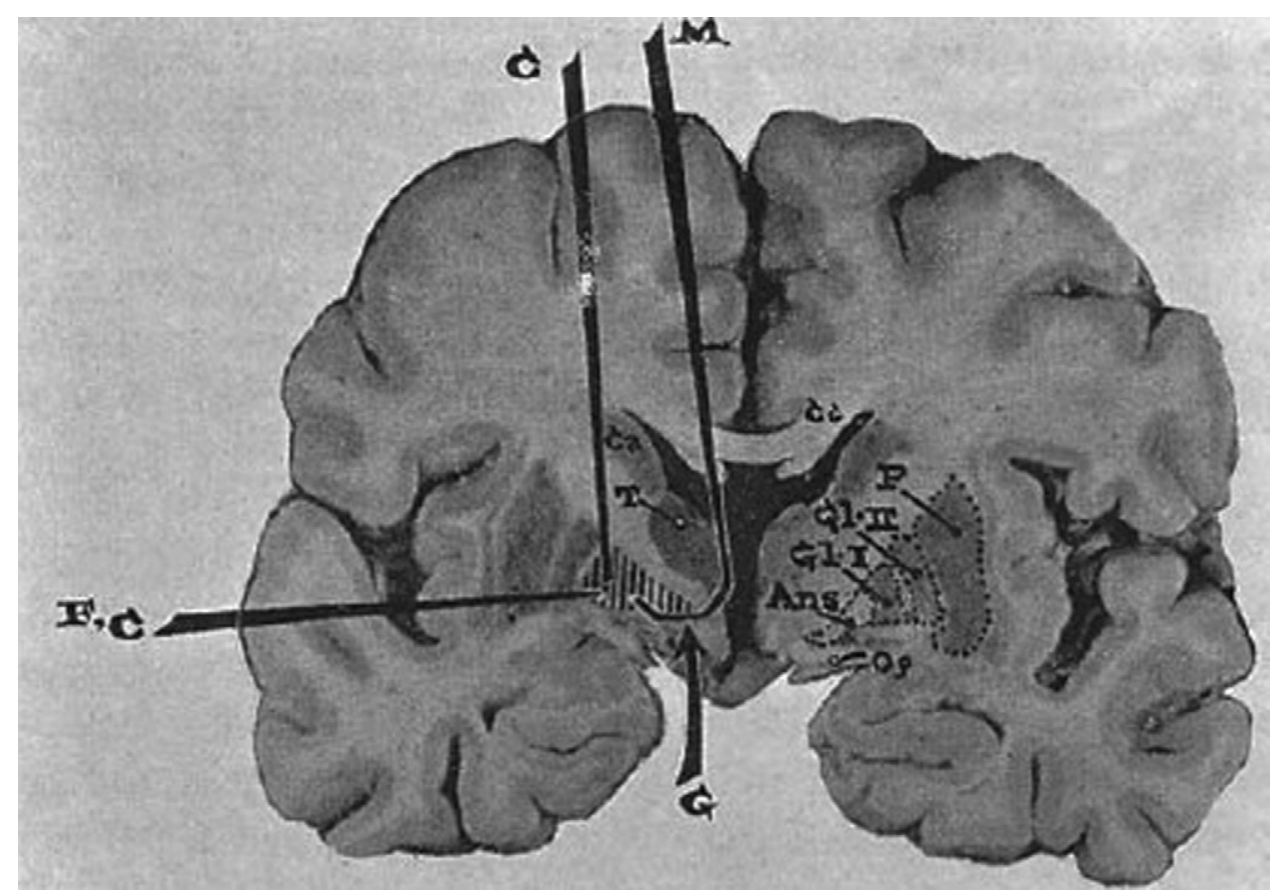

FIG. 4. Meyer's approach to the basal ganglia. (Meyers R. The surgery of the hyperkinetic disorders. In: Vinken PJ, Bruyn GW, eds. Diseases of the Basal Ganglia. New York: North-Holland Publishing, 1968: 844-878.)

the introduction of L-dopa in $1968 .{ }^{11,17}$ Surgery for psychiatric disease had been decreasing since the introduction of chlorpromazine in 1954, and it effectively came to a halt, at least in most centers in the United States, in 1977, based on the recommendations of the National Commission for the Protection of Human Subjects of Biomedical and Behavioral Research. ${ }^{23}$

There was still some activity in stereotactic and functional neurosurgery, but it became less common and more restricted to specialty centers working on small numbers of patients, due to the epidemiology of the diseases considered and the significant expense required to maintain specialized operating theaters with equipment for ventriculography and intraoperative electrophysiology. In the 1950s, temporary electrodes had been implanted into various brain regions for the control of pain with good effects from stimulation. ${ }^{24} \mathrm{By}$ the early 1970s, there were reports of chronic deep brain stimulation (DBS) systems implanted into the thalamus for chronic pain. ${ }^{25,26}$ Medtronic (Minneapolis, MN) established its Neurological Division in 1976, focusing on device development for DBS to treat chronic pain. ${ }^{27}$ Concurrently, other groups were working on DBS for the persistent vegetative state, ${ }^{28-30}$ and Irving Cooper was placing electrodes over the cerebellum and into the deep thalamic nuclei for cerebral palsy, spasticity, and epilepsy. ${ }^{31}$

Cooper reported his results from chronic cerebellar stimulation in over 200 patients in 1977 (reviewed in reference 30). Although these results were excellent, there was significant concern about whether the improvements were meaningful, as well as the subjective nature of his rating scales. The Food and Drug Administration (FDA) convened a meeting entitled "Safety and Efficacy of Implanted Neuroaugmentative Devices." Responding to these concerns, Cooper performed a short-term, double-blind study of cerebellar stimulation for spasticity. Each night, either a disguised piece of paper or a piece of aluminum foil (which would block transmission) was placed between the radiofrequency transmitter and the receiver. There was no correlation of the opinions of efficacy between the patients and clinicians and whether the device was active or not. Although Cooper faulted the trial design, multiple subsequent trials also failed to show efficacy. It became clear that there was a significant placebo effect.

While this was perceived as a significant step backward for Cooper and the field in general, this experience pointed to an inherent advantage of DBS (i.e., the ability to perform double-blinded, prospective randomized trials for a surgical procedure). Although there has been significant controversy about the ethics behind performing sham surgical procedures for fetal transplantation for $\mathrm{PD},{ }^{32}$ this is not an issue for DBS, as long as the patient does not feel paresthesia with stimulation. All patients in a trial can undergo initial implantation of their system. Without the patient or the evaluating physician knowing in which group they are, some of the systems can be left off for some specified period of time in a crossover design. Given the strength of the placebo effect in patients with movement disorders and psychiatric disease, ${ }^{33-35}$ this is an 


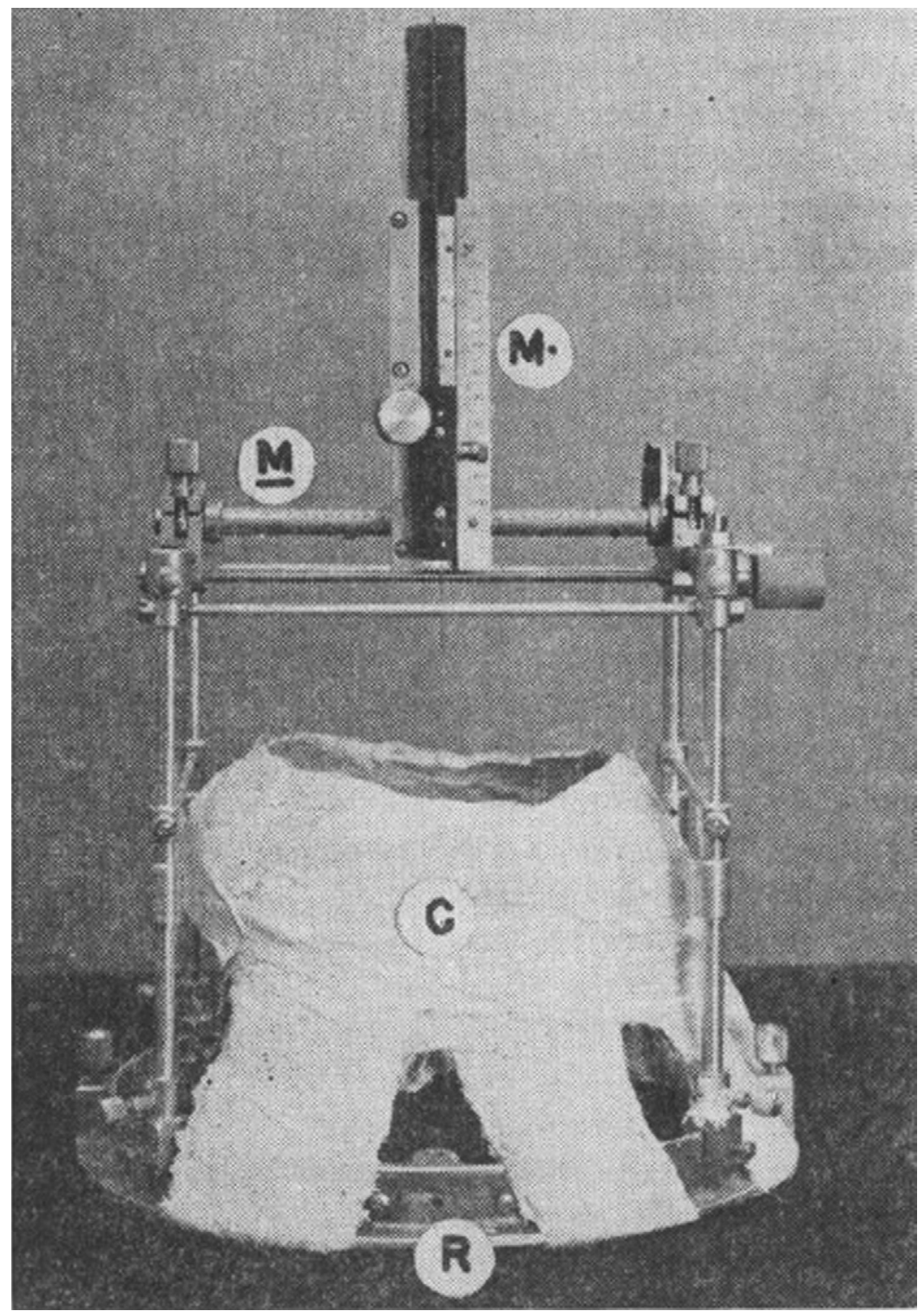

FIG. 5. Spiegel et al.'s ${ }^{12}$ stereotactic apparatus (side view). $R=$ ring; $C=$ cast of plaster of Paris; $M \cdot=$ millimeter scale on needle holder; $\underline{M}=$ millimeter scale for movement in sagittal direction. Reprinted with permission from Spiegel et al. SCIENCE 1947;106:349-50.

important, if not essential, tool for demonstrating efficacy if open label trials seem promising.

\section{THE RESURGENCE OF SURGICAL TREATMENT FOR MOVEMENT DISORDERS}

Although surgery for PD dropped off precipitously with the advent of L-dopa, many groups continued to perform thalamotomies for tremor of various etiologies (reviewed in reference 36). In 1991, both Benabid et al's ${ }^{37}$ and Blond and Siegfried's ${ }^{38}$ groups reported on thalamic DBS for tremor. Subsequent studies found that thalamic DBS was safer than thalamotomy and especially bilateral thalamotomy. ${ }^{36}$ These studies led to the approval of Medtronic's Activa system for tha- lamic DBS for essential tremor and tremor related to PD in 1997.

There was a gradual realization that L-dopa was not the magic bullet that it had initially seemed to be. ${ }^{17}$ Patients were requiring increased and more frequent dosing with motor fluctuations and L-dopa induced dyskinesias as their disease progressed. By the 1980s, groups in Sweden and Mexico were reporting transplantation of autologous adrenal tissue into the brains of patients with PD via both open craniotomy and stereotactic approaches. ${ }^{39,40}$ Although the thalamus had been the preferred target for patients with PD prior to the introduction of L-dopa, ${ }^{17}$ Laitinen et al. ${ }^{41,42}$ popularized pallidotomy as the principal procedure for patients with advanced, medically 
refractory PD in the early 1990s. There were several reasons for this change: 1) the patients may have had more advanced disease in the 1990s than in the 1950s and 1960s since they had failed L-dopa, 2) DeLong et al's ${ }^{43}$ nonhuman primate model pointed to a more important role in the circuitry of PD for the globus pallildus pars interna (GPi) than the ventrointermedialis nucleus (Vim) of the thalamus, and 3) better outcome measures may have detected differences that were initially missed in the 1950s and 1960s. ${ }^{21}$

Given the familiarity with DBS for pain at the time, it did not take long for groups to report on pallidal DBS as an alternative to pallidotomy. ${ }^{44}$ Similar to the experience with thalamic DBS, it became apparent that the risks associated with pallidal DBS were less than those with pallidotomy, ${ }^{44-47}$ leading to the approval of Medtronic's Activa system for GPi DBS for PD in 2002.

Concurrently, Pollak et al's ${ }^{48}$ group in Grenoble began working on a new target: the subthalamic nucleus of Luys (STN). Although the dorsal STN and the zona incerta had been targeted in the $1960 \mathrm{~s},{ }^{49}$ this region of the brain had been avoided by most stereotactic surgeons in the 1950s and 1960s due to fear of causing ballism, a well described movement disorder after strokes in this region. However, DeLong et al's ${ }^{43}$ experiments led to an understanding of the importance of the STN in the brain circuitry involved in PD and a nonhuman primate model of PD was developed in which to test these ideas, the N-methyl-4-phenyl-1,2,3,6-tetrahydropyridine (MPTP) monkey. ${ }^{50}$ It was found that lesions or high-frequency stimulation of the STN in MPTP monkeys could alleviate tremor, rigidity, and bradykinesia without causing ballism. ${ }^{51-53}$ The Grenoble group reported on STN DBS in a single patient in $1994 .{ }^{48}$ STN DBS has been found to be effective for bradykinesia, tremor, and rigidity. ${ }^{54,55}$ In addition, there is a significant decrease in the amount of dopaminergic medication needed after surgery. Medtronic's Activa system for STN DBS was approved by the FDA in 2002.

In parallel, as reviewed in $\mathrm{Yu}$ and $\mathrm{Neimat}^{55}$ in this issue, DBS of the GPi and, to a lesser extent, the STN were explored in the treatment of both generalized and segmental dystonia. The FDA granted Humanitarian Device Exemption (HDE) for the use of Medtronic's Activa system for GPi and STN DBS for generalized and segmental primary dystonia in 2003. Although HDEs are designed for so-called orphan diseases, where the incidence is so low that it is not feasible to power a pivotal trial, there has been a recent European, prospective, randomized double-blind trial of GPi DBS for primary dystonia that has shown efficacy. ${ }^{56}$

Due to the superior safety of GPi and Vim DBS over pallidotomy and thalamotomy, there has been a gradual abandonment of lesional techniques in favor of DBS, at least in the United States. ${ }^{57}$ In 1996, 336 thalamotomies or pallidotomies were performed in the United States. Since 1996, more than 40,000 people worldwide have undergone placement of Medtronic Activa DBS systems for PD, essential tremor, and dystonia (personal communication, Cindy Resman, Medtronic, Inc., Minneapolis, $\mathrm{MN})$. Of these, the vast majority have been for PD.

\section{WHAT HAPPENED TO DBS FOR PAIN?}

As previously noted, between the introduction of Ldopa in 1968 and the advent of Vim, GPi, and STN DBS in the early 1990s, DBS was mostly used and explored for pain. However, in 1989, the FDA withdrew approval of DBS for pain. ${ }^{17}$ In response, Medtronic sponsored two multi-center, open-label trials to demonstrate efficacy of this technology. ${ }^{58}$ These trials were completed in 1993 and 1998, but did not show the hoped for efficacy, with only an approximate $20 \%$ response rate. The results were reported to the FDA, but were not reported in the scientific literature until 2001.

\section{THE FUTURE OF DBS FOR MOVEMENT DISORDERS}

Although there are multiple studies demonstrating efficacy of DBS for movement disorders, there are still many questions that require answers. DBS has been shown to be effective in people with medically refractory $\mathrm{PD}$ in prospective controlled trials in both motor function and quality of life. ${ }^{55,59}$ However, it is unclear what the effects of DBS are on the nonmotor aspects of PD. This is being rigorously examined by the group at the University of Florida (Clinicaltrials.gov, Identifier No. NCT00360009). It is still unclear at what point a patient should be deemed to have failed medical therapy. How many drug trials are required? Might patients have better outcomes if they undergo DBS earlier in the course of their disease before they are no longer able to work, as is being examined (Clinicaltrials.gov, Identifier No. NCT00282152 and NCT00354133)? While there has been one pilot prospective, randomized trial of GPi versus STN DBS, ${ }^{60}$ results from the larger Veteran's Affairs trial (Clinicaltrials.gov, Identifier No. NCT00056563) are not available. It is unclear whether certain subgroups might be more appropriate for one modality than the other. ${ }^{61}$

In addition, although there has been one rigorous trial examining the efficacy of GPi DBS in primary dystonia, ${ }^{56}$ the reports of DBS for secondary dystonia consist of small case series. ${ }^{62}$ Trials are underway to examine the efficacy of DBS for tardive dystonia (Clinicaltrials. gov, Identifier No. NCT00331669), and postanoxic generalized dystonia (Clinicaltrials.gov, Identifier No. NCT00169338). Although the FDA granted an HDE for GPi and STN DBS for dystonia, the efficacy of STN 
DBS for primary dystonia has not been demonstrated rigorously to date.

\section{FUTURE OF DBS FOR OTHER DISORDERS}

The knowledge and experience gained with DBS for the treatment of pain and movement disorders are now being leveraged and applied to other disorders. As basic science and functional imaging with MRI or positron emission tomography suggest roles for discrete areas of the brain in the pathogenesis of disease states, they are being considered for neuromodulation via DBS. ${ }^{63,64}$ The reversible nature of stimulation is an attractive feature and clinical conditions that were not believed to be surgically treatable are now being considered suitable for DBS therapy. Among the most promising new applications of DBS at present are psychiatric disorders, as reviewed by Larson ${ }^{65}$ in this issue. This field is clearly of great interest due to the epidemiology of these diseases, especially major depression. There are estimated to be 180,000 people in the United States less than 70 years of age with PD (unpublished data from reference ${ }^{66}$ ). Of these, only a small proportion will be candidates for DBS. However, depression affects more than 18 million people in the United States. ${ }^{67}$ Of these, approximately $30 \%$ will fail adequate trials of up to four different classes of antidepressants. ${ }^{68}$ An additional $35 \%$ will fail electroconvulsive therapy, ${ }^{69}$ leaving potentially 2 million Americans with treatment refractory depression. Medtronic $^{65}$ and ANS systems (Advanced Neurologic Systems, Plano, TX; Clinicaltrials.gov, Identifier No. NCT00367003) are both being used in trials of DBS for treatment refractory depression.

In addition to psychiatric disorders, DBS has also been suggested as a potential therapy for hypertension, obesity, and eating disorders. Autonomic changes have been classically reported in patients with chronic pain receiving periaqueductal/periventricular grey (PAG/PVG) stimulation. In a recent report, Green et al. ${ }^{70}$ have shown that an increase or decrease in blood pressure could be induced with DBS in different locations of the PAG/ PVG region in a patient with chronic neuropathic pain. As for obesity or eating disorders, in spite of anecdotal reports at meetings, no patients treated with DBS have been published so far.

Although DBS for pain has been largely abandoned, ${ }^{58}$ the group from Milan has explored DBS of the posterior hypothalamus for cluster headache on the basis of positron emission tomographic studies, which showed overactivity in this region. ${ }^{64} \mathrm{~A}$ recent study has re-explored DBS for the minimally conscious state after traumatic brain injury using a 6-month, double-blind, alternating crossover design. ${ }^{71}$ In epilepsy, open-label studies with a small number of patients have been reported with stimulation of the hippocampus, thalamus, and STN. ${ }^{72}$ In addition, prospective, randomized, multicenter studies are currently being carried out to assess the efficacy of anterior thalamic nucleus and STN DBS. Results of these trials are much awaited.

\section{TECHNOLOGICAL FEATURES}

Current DBS systems generally include a quadripolar electrode inserted into the brain, inline extensions running behind the ear, and an internal pulse generator (IPG) implanted either on top of or deep to the pectoralis fascia (FIG. 6).$^{73}$ Depending on the model, current IPGs can accommodate either one or two electrodes. The IPG is then programmed transcutaneously via a PDA-like device with a magnet. The patient is given a controller with which to turn the device on and off. Some IPGs can also be programmed to allow the patient to vary the voltage within set limits.

It is likely that some technological features of this therapy will be improved in the near future. Even for conditions in which a good experience has been acquired over the years (i.e., PD), the number of hours and resources dedicated to the management of patients treated with DBS is fairly high. The adjustment of optimal stimulation parameters and the management of postoperative medication changes are time consuming and require multiple clinic visits. In the future, we will need to develop ways of simplifying the process of programming and adjusting stimulation parameters, as is being developed with artificial neural networks for spinal cord stimulator programming. ${ }^{74}$ The identification of the ideal surgical candidates and the most responsive clinical symptoms in each condition, as well as the development of surrogate electrophysiologic and imaging markers, may all contribute to improved outcomes and reduce the amount of postoperative time spent for programming. In addition, as is currently the case for cardiac pacemakers, the ability to program DBS devices through remote access, telephone lines or via the Internet might potentially be very useful.

Another area of recent advance that still requires more research relates to the power source for DBS. As currently used for movement disorders, the lifespan of the batteries used in regular IPGs is in the order of 5 years. ${ }^{75}$ However, for other applications (e.g., anterior capsule DBS for obsessive compulsive disorder), the power required to control the patients' symptomatology is significantly higher. ${ }^{76,77}$ Under these circumstances, the frequent replacement of the batteries is of significant concern. Rechargeable batteries are now available for the treatment of pain syndromes with spinal cord stimulation. The number of times the patients need to recharge the IPG varies according to the usage of the device. Although no long-term studies have been conducted, the advertised life span of rechargeable batteries is in the 
A

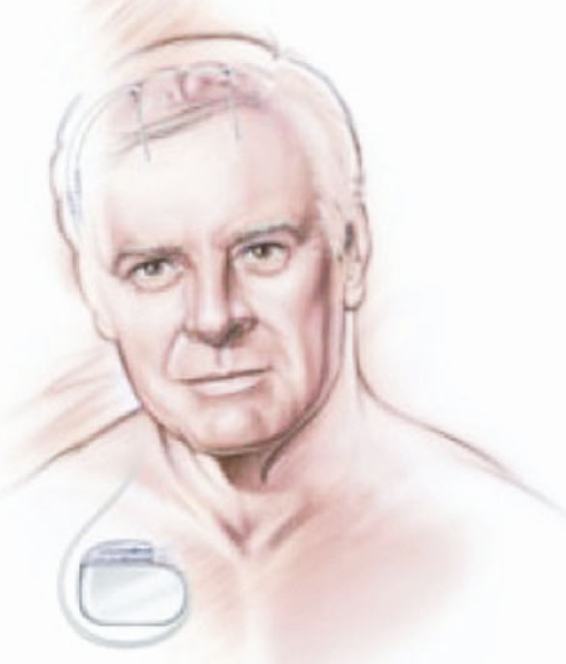

B

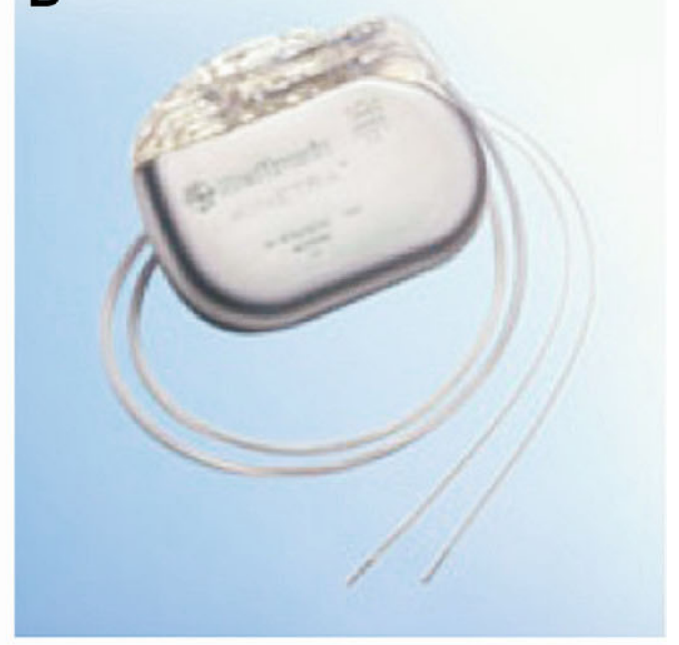

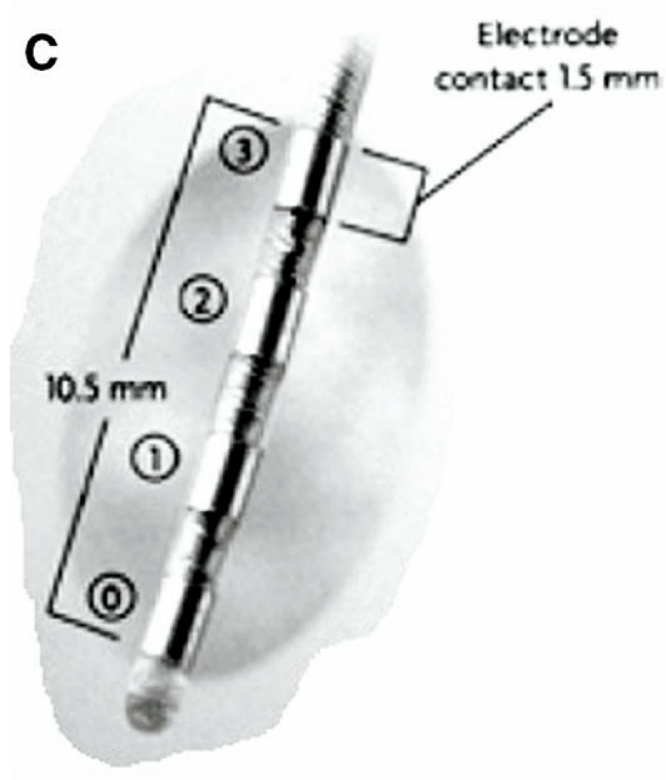
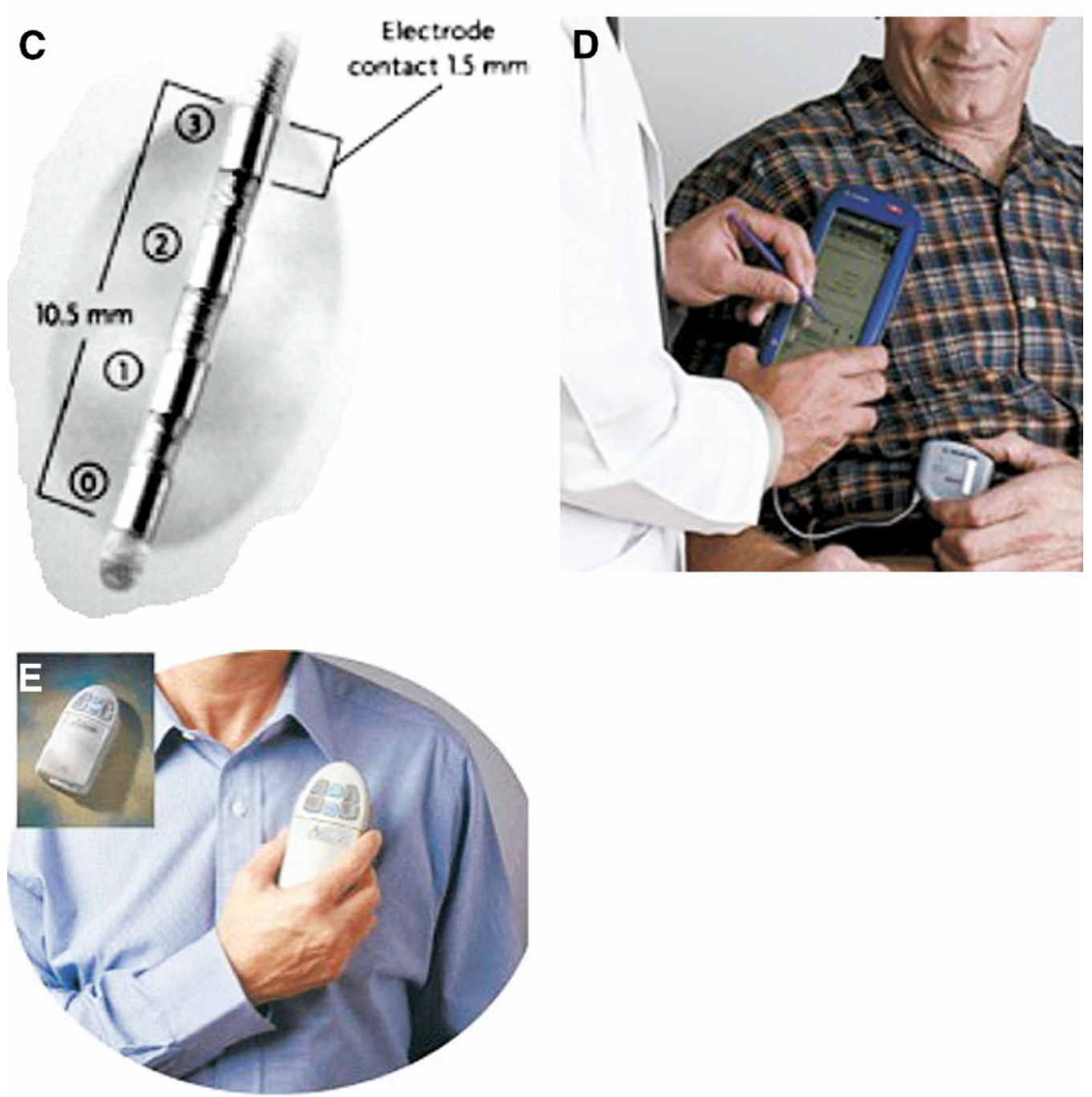

FIG. 6. Activa therapy system (courtesy of Medtronic, Inc.). A, Schematic of implantated device. B, Kinetra IPG (Medtronic Inc.) with two leads. C, Medtronic 3387 DBS electrode. D, physician programmer. E, patient controller. 
order of 10 to 15 years, after which the pulse generator has to be replaced. Another feature of interest would be the development of miniaturized pulse generators that fit within a drilled out trough in the skull. ${ }^{78}$ This would be a significant advance in the case of DBS for cervical dystonia, where there is a high incidence of lead fracture due to the dystonic neck movements and postures associated with the disease. ${ }^{79}$ Improvements in battery technology will be required.

In addition to new developments in pulse generators, newer designs in the electrode arrays, geometry, and orientation of active contacts may also play an important part in optimizing the therapeutic efficacy and minimizing the adverse effects that may be associated with DBS. For example, paddles with two or three columns of leads and multiple contacts are now available for spinal cord stimulation for current sculpting. Different combinations of contacts might be useful in maximizing the therapeutic effects of stimulation and reducing unwanted current spread to adjacent structures, which can cause adverse side effects.

All current systems for DBS deliver continuous stimulation. It is unknown if "closed loop" stimulation, where the device delivers stimulation based on the local electrical activity, as is being explored for epilepsy, ${ }^{78}$ would be useful for other disorders.

\section{IS THERE STILL A ROLE FOR LESIONAL SURGERY?}

There are patients for whom DBS is not an option due to the expense of the system. The cost of the system varies from country to country based on healthcare delivery systems. The cost to the patient depends on the medical insurance structure of the particular country. Medtronic estimates the cost for a bilateral implantation as $\$ 50,000$ to $\$ 60,000$, including the cost of the device as well as hospital and physician's fees. ${ }^{80}$ For patients living in remote areas for whom frequent visits for postoperative programming are not feasible, lesions are a reasonable option. As a result, there continue to be many publications, mostly from outside North America and Europe, regarding thalamotomy, pallidotomy, and subthalamotomy. ${ }^{81-86}$

Lesions (generally unilateral to decrease the risk) created with stereotactic radiosurgery are options for patients who are poor operative risks due to their general medical condition or coagulopathy. ${ }^{87-90}$ Although there are clearly complications from stereotactic radiosurgery, as with any procedure, the overall complication rate is unclear, because many patients who suffer them go to other centers. $^{91,92}$

In addition, while there is evidence that bilateral pallidal and thalamic DBS are safer than pallidotomy and thalamotomy, respectively, ${ }^{36,47}$ this may not be the case for other diseases and/or other targets. For example, of the 32 patients reported to have undergone DBS for obsessive compulsive disorder (OCD), results have not been markedly better than for cingulotomy and there has been one mortality due to suicide. ${ }^{77,93}$ In addition, patients suffered acute depression and OCD when their IPGs became depleted, which was not infrequent, given the high voltages used. ${ }^{77}$ Although DBS may be safer than capsulotomy, it is hard to argue at this time that it is should replace cingulotomy, given that there were no deaths and minimal morbidity in the 800 cingulotomies performed over 40 years at Massachusetts General Hospital, ${ }^{94}$ and the fact that there is no risk of rebound phenomenon from battery exhaustion. However, while industry is likely to support trials to assess the efficacy of DBS, it will fall to governmental agencies to fund studies comparing DBS to lesional techniques.

\section{CONCLUSIONS}

With any novel technology, a new set of issues arises, particularly economic costs, and the need for training of specialized physicians, nurses, and entire teams to deal with patients with these complex disorders and devices. Overall, however, DBS has led to improvements in function and quality of life for many people suffering from movement disorders. The ability to turn the device on and off has led to the ability to ethically perform randomized, blinded, crossover trials to assess efficacy. With functional imaging and basic science techniques identifying discrete areas of the brain involved with different neurological and psychiatric conditions, the field will continue to expand into new indications.

\section{REFERENCES}

1. Rossi U. The history of electrical stimulation of the nervous system for the control of pain. In: Simpson BA, ed. Electrical stimulation and the relief of pain, 1st ed. Amsterdam: Elsevier B.V., 2003: 5-16.

2. Debru A. The power of torpedo fish as a pathological model to the understanding of nervous transmission in Antiquity. C R Biol 2006;329:298-302.

3. Kellaway P. The part played by the electric fish in the early history of bioelectricity and electrotherapy. Bull Hist Med 1946;20:112137.

4. Devinsky O. Electrical and magnetic stimulation of the central nervous system: historical overview. In: Devinsky O, Beric A, Dogali M, eds. Electrical and magnetic stimulation of the brain and spinal cord, 1st ed. New York: Raven Press, 1993:1-16.

5. Fritsch G, Hitzig E. The electrical excitability of the cerebrum. In: Wilkins RW, ed. Neurosurgical classics, 1st ed: American association of neurological surgeons, 1992:15-27.

6. Morgan JP. The first reported case of electrical stimulation of the human brain. J Hist Med Allied Sci 1982;37:51-64.

7. Bartholow R. Medical electricity: a practical treatise on the applications of electricity to medicine and surgery, 2nd ed. Philadelphia: Henry C. Lea's Son \& Co., 1882.

8. Horsley V. Case of occipital encephalocele in which a correct diagnosis was obtained by means of the induced current. Brain 1884;7:228-243 
9. Vilensky JA, Gilman S. Horsley was the first to use electrical stimulation of the human cerebral cortex intraoperatively. Surg Neurol 2002;58:425-426.

10. Horsley V. Remarks on the surgery of the central nervous system. Br Med J 1890;2:1286-1292.

11. Gildenberg PL. Evolution of basal ganglia surgery for movement disorders. Stereotact Funct Neurosurg 2006;84:131-135.

12. Spiegel EA, Wycis HT, Marks M, Lee AS. Stereotactic apparatus for operations on the human brain. Science 1947;106:349-350.

13. Horsley V, Clarke R. The structure and functions of the cerebellum examined by a new method. Brain 1908;31:45-124.

14. Jensen RL, Stone JL, Hayne RA. Introduction of the human Horsley-Clarke stereotactic frame. Neurosurgery 1996;38:563-567; discussion 567.

15. Monnier M. Contributions experimenteles a la physiologie du trone cerebral chez l'homme: III. Stimulation et coagulation du lemniscus median. Helvet. Physiol et Pharmacol. acta 1951;9:C10.

16. Hassler R, Reichert T. Indikationen und Localizations-Methode der gezielten Hirnoperationen. Nervenarzt 1954;25:441.

17. Gildenberg PL. History of movement disorder surgery. In: Lozano AM, ed. Movement disorder surgery, 1st ed. Basel: Karger, 2000: $1-20$.

18. Ervin FR, Mark VH. Stereotactic thalamotomy in the human. Part II, Physiologic observations on the human thalamus. Arch Neurol $1960 ; 3: 368-380$.

19. Guiot G, Hardy J, Albe-Fessard D. Delimitation precise des structures sous-corticales et identification de noyaux thalamiques chez l'homme par l'electrophysioligie stereotaxique. Neurochirurgia 1961;5:1-18.

20. Tasker RR, Organ LW, Hawrylyshyn PA. The thalamus and midbrain of man. Springfield: Charles C. Thomas, 1982.

21. Tasker RR. One man's recollection of 50 years of functional and stereotactic neurosurgery. Neurosurgery 2004;55:968-974; discussion 974-966.

22. Chardack WM, Gage AA, Greatbatch W. A transistorized, selfcontained, implantable pacemaker for the long-term correction of complete heart block. Surgery 1960;48:643-654.

23. Kopell BH, Rezai AR. Psychiatric neurosurgery: a historical perspective. In: Rezai AR, Rasmussen SA, Greenberg BD, eds. Surgery for psychiatric disorders. Philadelphia: W.B. Saunders Company, 2003:181-198.

24. Rezai AR, Lozano AM. Deep brain stimulation for chronic pain. In: Burchiel KJ, ed. Surgical management of pain, 1st ed. New York: Thieme, 2002:565-576.

25. Hosobuchi Y, Adams JE, Rutkin B. Chronic thalamic stimulation for the control of facial anesthesia dolorosa. Arch Neurol 1973; 29:158-161.

26. Mazars G, Merienne L, Cioloca C. [Treatment of certain types of pain with implantable thalamic stimulators]. Neurochirurgie 1974; 20:117-124.

27. About Medtronic_-Our History, 1971-1980 [online]. Available at: http://www.medtronic.com/corporate/1971_1980.html. Accessed October 21, 2007.

28. Sturm V, Kuhner A, Schmitt HP, Assmus H, Stock G. Chronic electrical stimulation of the thalamic unspecific activating system in a patient with coma due to midbrain and upper brain stem infarction. Acta Neurochir (Wien) 1979;47:235-244.

29. Hassler R, Ore GD, Bricolo A, Dieckmann G, Dolce G. EEG and clinical arousal induced by bilateral long-term stimulation of pallidal systems in traumatic vigil coma. Electroencephalogr Clin Neurophysiol 1969;27:689-690.

30. Hassler R, Ore GD, Dieckmann G, Bricolo A, Dolce G. Behavioural and EEG arousal induced by stimulation of unspecific projection systems in a patient with post-traumatic apallic syndrome. Electroencephalogr Clin Neurophysiol 1969;27:306-310.

31. Rosenow J, Das K, Rovit RL, Couldwell WT, Irving S. Cooper and his role in intracranial stimulation for movement disorders and epilepsy. Stereotact Funct Neurosurg 2002;78:95-112.

32. Freed CR, Breeze RE, Fahn S. Placebo surgery in trials of therapy for Parkinson's disease. N Engl J Med 2000;342:353-354; author reply $354-355$.

33. Cavanna AE, Strigaro G, Monaco F. Brain mechanisms underlying the placebo effect in neurological disorders. Funct Neurol 2007;22:89-94.

34. Pollo A, Torre E, Lopiano L, et al. Expectation modulates the response to subthalamic nucleus stimulation in Parkinsonian patients. Neuroreport 2002;13:1383-1386.

35. Mercado R, Constantoyannis C, Mandat T, et al. Expectation and the placebo effect in Parkinson's disease patients with subthalamic nucleus deep brain stimulation. Mov Disord 2006;21:1457-1461.

36. Schwalb JM, Lozano AM. Surgical management of tremor. Neurosurg Q 2004;14:60-68.

37. Benabid AL, Pollak P, Gervason C, et al. Long-term suppression of tremor by chronic stimulation of the ventral intermediate thalamic nucleus. Lancet 1991;337:403-406.

38. Blond S, Siegfried J. Thalamic stimulation for the treatment of tremor and other movement disorders. Acta Neurochir Suppl (Wien) 1991;52:109-111.

39. Madrazo I, Drucker-Colin R, Diaz V, Martinez-Mata J, Torres C, Becerril JJ. Open microsurgical autograft of adrenal medulla to the right caudate nucleus in two patients with intractable Parkinson's disease. N Engl J Med 1987;316:831-834.

40. Backlund EO, Granberg PO, Hamberger B, et al. Transplantation of adrenal medullary tissue to striatum in parkinsonism: first clinical trials. J Neurosurg 1985;62:169-173.

41. Laitinen LV, Bergenheim AT, Hariz MI. Leksell's posteroventral pallidotomy in the treatment of Parkinson's disease. J Neurosurg 1992;76:53-61.

42. Laitinen LV, Bergenheim AT, Hariz MI. Ventroposterolateral pallidotomy can abolish all parkinsonian symptoms. Stereotact Funct Neurosurg 1992;58:14-21.

43. DeLong MR, Georgopoulos AP, Crutcher MD, Mitchell SJ, Richardson RT, Alexander GE. Functional organization of the basal ganglia: contributions of single-cell recording studies. Ciba Found Symp 1984;107:64-82.

44. Siegfried J, Lippitz B. Bilateral chronic electrostimulation of ventroposterolateral pallidum: a new therapeutic approach for alleviating all parkinsonian symptoms. Neurosurgery 1994;35:11261129; discussion 1129-1130.

45. Ghika J, Villemure JG, Fankhauser H, Favre J, Assal G, GhikaSchmid F. Efficiency and safety of bilateral contemporaneous pallidal stimulation (deep brain stimulation) in levodopa-responsive patients with Parkinson's disease with severe motor fluctuations: a 2-year follow-up review. J Neurosurg 1998;89:713-718.

46. Kumar R, Lang AE, Rodriguez-Oroz MC, et al. Deep brain stimulation of the globus pallidus pars interna in advanced Parkinson's disease. Neurology 2000;55:S34-39.

47. Kumar R, Lozano AM, Montgomery E, Lang AE. Pallidotomy and deep brain stimulation of the pallidum and subthalamic nucleus in advanced Parkinson's disease. Mov Disord 1998;13(suppl 1): 73-82.

48. Pollak P, Benabid AL, Gross C, et al. [Effects of the stimulation of the subthalamic nucleus in Parkinson disease]. Rev Neurol (Paris) 1993;149:175-176.

49. Andy OJ, Jurko MF, Sias FR, Jr.Subthalamotomy in treatment of parkinsonian tremor. J Neurosurg 1963;20:860-870.

50. Burns RS, Chiueh CC, Markey SP, Ebert MH, Jacobowitz DM, Kopin IJ. A primate model of parkinsonism: selective destruction of dopaminergic neurons in the pars compacta of the substantia nigra by N-methyl-4-phenyl-1,2,3,6-tetrahydropyridine. Proc Natl Acad Sci U S A 1983;80:4546-4550.

51. Aziz TZ, Peggs D, Sambrook MA, Crossman AR. Lesion of the subthalamic nucleus for the alleviation of 1-methyl-4-phenyl1,2,3,6-tetrahydropyridine (MPTP)-induced parkinsonism in the primate. Mov Disord 1991;6:288-292.

52. Benazzouz A, Gross C, Feger J, Boraud T, Bioulac B. Reversal of rigidity and improvement in motor performance by subthalamic high-frequency stimulation in MPTP-treated monkeys. Eur J Neurosci 1993;5:382-389.

53. Bergman H, Wichmann T, DeLong MR. Reversal of experimental parkinsonism by lesions of the subthalamic nucleus. Science 1990; 249:1436-1438.

54. Hamani C, Richter E, Schwalb JM, Lozano AM. Bilateral subthalamic nucleus stimulation for Parkinson's disease: a systematic 
review of the clinical literature. Neurosurgery 2005;56:1313-1321; discussion 1321-1314.

55. Yu H, Neimat JS. The treatment of movement disorders by neural deep brain stimulation. Neurotherapeutics 2008;5:26-36.

56. Kupsch A, Benecke R, Muller J, et al. Pallidal deep-brain stimulation in primary generalized or segmental dystonia. N Engl J Med 2006;355:1978-1990.

57. Eskandar EN, Flaherty A, Cosgrove GR, Shinobu LA, Barker FG, 2nd. Surgery for Parkinson disease in the United States, 1996 to 2000: practice patterns, short-term outcomes, and hospital charges in a nationwide sample. J Neurosurg 2003;99:863-871.

58. Coffey RJ. Deep brain stimulation for chronic pain: results of two multicenter trials and a structured review. Pain Med 2001;2:183192.

59. Deuschl G, Schade-Brittinger C, Krack P, et al. A randomized trial of deep-brain stimulation for Parkinson's disease. N Engl J Med 2006;355:896-908.

60. Burchiel KJ, Anderson VC, Favre J, Hammerstad JP. Comparison of pallidal and subthalamic nucleus deep brain stimulation for advanced Parkinson's disease: results of a randomized, blinded pilot study. Neurosurgery 1999;45:1375-1382; discussion 13821374.

61. Rothlind JC, Cockshott RW, Starr PA, Marks WJ, Jr. Neuropsychological performance following staged bilateral pallidal or subthalamic nucleus deep brain stimulation for Parkinson's disease. J Int Neuropsychol Soc 2007;13:68-79.

62. Holloway KL, Baron MS, Brown R, Cifu DX, Carne W, Ramakrishnan V. Deep brain stimulation for dystonia: a meta-analysis. Neuromodulation 2006;9:253-261.

63. Mayberg HS, Lozano AM, Voon V, et al. Deep brain stimulation for treatment-resistant depression. Neuron 2005;45:651-660.

64. Leone M, Franzini A, Felisati G, et al. Deep brain stimulation and cluster headache. Neurol Sci 2005;26(suppl 2):s138-s139.

65. Larson PS. Deep brain stimulation for psychiatric disorders. Neurotherapeutics 2008;5:50-58.

66. Dorsey ER, Constantinescu R, Thompson JP, et al. Projected number of people with Parkinson disease in the most populous nations, 2005 through 2030. Neurology 2007;68:384-386.

67. Keller MB. Issues in treatment-resistant depression. J Clin Psychiatry $2005 ; 66: 5-12$.

68. Rush AJ, Trivedi MH, Wisniewski SR, et al. Acute and longerterm outcomes in depressed outpatients requiring one or several treatment steps: a STAR*D report. Am J Psychiatry 2006;163: 1905-1917.

69. Pagnin D, de Queiroz V, Pini S, Cassano GB. Efficacy of ECT in depression: a meta-analytic review. J Ect 2004;20:13-20.

70. Green AL, Wang S, Bittar RG, et al. Deep brain stimulation: a new treatment for hypertension? J Clin Neurosci 2007;14:592-595.

71. Schiff ND, Giacino JT, Kalmar K, et al. Behavioural improvements with thalamic stimulation after severe traumatic brain injury. Nature 2007;448:600-603.

72. Halpern CH, Samadani U, Litt B, Jaggi JL, Baltuch GH. Deep brain stimulation for epilepsy. Neurotherapeutics 2008;5:59-67.

73. Schwalb JM, Riina HA, Skolnick B, Jaggi JL, Simuni T, Baltuch $\mathrm{GH}$. Revision of deep brain stimulator for tremor. Technical note. J Neurosurg 2001;94:1010-1012.

74. North RB, McNamee JP, Wu L, Piantadosi S. Artificial neural networks: application to electrical stimulation of the human nervous system. Neurosurg Focus 1997;2:e1.
75. Bin-Mahfoodh M, Hamani C, Sime E, Lozano AM. Longevity of batteries in internal pulse generators used for deep brain stimulation. Stereotact Funct Neurosurg 2003;80:56-60.

76. Nuttin BJ, Gabriels LA, Cosyns PR, et al. Long-term electrical capsular stimulation in patients with obsessive-compulsive disorder. Neurosurgery 2003;52:1263-1272; discussion 1272-1264.

77. Greenberg BD, Malone DA, Friehs GM, et al. Three-year outcomes in deep brain stimulation for highly resistant obsessivecompulsive disorder. Neuropsychopharmacology 2006;31:23842393.

78. Sun FT, Morrell MJ, Wharen RE. Responsive cortical stimulation for the treatment of epilepsy. Neurotherapeutics 2008;5:68-74.

79. Yianni J, Nandi D, Shad A, Bain P, Gregory R, Aziz T. Increased risk of lead fracture and migration in dystonia compared with other movement disorders following deep brain stimulation. J Clin Neurosci 2004;11:243-245.

80. Questions and answers about Medtronic Activa Parkinson's control therapy [online]. Available at: http://www.medtronic.com/ neuro/parkinsons/activa_qa4.html\#9. Accessed October 23, 2007.

81. Blomstedt P, Hariz MI. Are complications less common in deep brain stimulation than in ablative procedures for movement disorders? Stereotact Funct Neurosurg 2006;84:72-81.

82. Chung SJ, Hong SH, Kim SR, Lee MC, Jeon SR. Efficacy and safety of simultaneous bilateral pallidotomy in advanced Parkinson's disease. Eur Neurol 2006;56:113-118.

83. Su PC, Tseng HM, Liu HM, Yen RF, Liou HH. Subthalamotomy for advanced Parkinson disease. J Neurosurg 2002;97:598-606.

84. Patel NK, Heywood P, O'Sullivan K, McCarter R, Love S, Gill SS Unilateral subthalamotomy in the treatment of Parkinson's disease. Brain 2003;126:1136-1145.

85. Su PC, Tseng HM, Liu HM, Yen RF, Liou HH. Treatment of advanced Parkinson's disease by subthalamotomy: one-year results. Mov Disord 2003;18:531-538.

86. Alvarez L, Macias R, Lopez G, et al. Bilateral subthalamotomy in Parkinson's disease: initial and long-term response. Brain 2005; 128:570-583.

87. Duma CM, Jacques D, Kopyov OV. The treatment of movement disorders using Gamma Knife stereotactic radiosurgery. Neurosurg Clin N Am 1999;10:379-389.

88. Young RF, Jacques S, Mark R, et al. Gamma knife thalamotomy for treatment of tremor: long-term results. J Neurosurg 2000; 93(suppl 3): 128-135.

89. Keep MF, Mastrofrancesco L, Erdman D, Murphy B, Ashby LS. Gamma knife subthalamotomy for Parkinson disease: the subthalamic nucleus as a new radiosurgical target. Case report. J Neurosurg 2002;97:592-599.

90. Ohye C, Shibazaki T, Zhang J, Andou Y. Thalamic lesions produced by gamma thalamotomy for movement disorders. J Neurosurg 2002;97:600-606.

91. Okun MS, Stover NP, Subramanian T, et al. Complications of gamma knife surgery for Parkinson disease. Arch Neurol 2001;58: 1995-2002.

92. Siderowf A, Gollump SM, Stern MB, Baltuch GH, Riina HA. Emergence of complex, involuntary movements after gamma knife radiosurgery for essential tremor. Mov Disord 2001;16:965-967.

93. Lipsman N, Neimat JS, Lozano AM. Deep brain stimulation for treatment-refractory obsessive-compulsive disorder: the search for a valid target. Neurosurgery 2007;61:1-11; discussion 11-13.

94. Cosgrove GR, Rauch SL. Stereotactic cingulotomy. Neurosurg Clin N Am 2003;14:225-235. 